\title{
Espiritualidad laica y espiritualidad atea
}

\author{
Espiritualidade laica e espiritualidade ateia \\ Secular Spirituality and Atheistic Spirituality
}

Francesc Torradeflot Freixes *

\begin{abstract}
Resumen
Se intenta ver la relación entre estas espiritualidades para desembocar en la que parece la única espiritualidad viable en la sociedad de conocimiento. Se analizan los textos de personalidades de referencia de ambas espiritualidades, como Feuerbach, Marx, Nietzsche o Comte Sponville, entre otros. Se observan específicamente algunos de los elementos esenciales de una espiritualidad atea: espíritu crítico y racionalidad, la centralidad y suficiencia del ser humano y su liberación de la sumisión y de la explotación, y una voluntad sin límites en lugar de pereza. Sin embargo, el objetivo principal es poner de relieve que hay un cultivo de la dimensión absoluta de la realidad más allá de las tradiciones religiosas y que este cultivo, en sociedades de cambio continuo, requiere, como propone Corbí, una nueva antropología, de un animal que habla con doble acceso a la realidad; así como una nueva epistemología, más allá de la mítica de anteriores paradigmas, que permita el uso meramente libre y simbólico de las sabidurías de la humanidad. Está en juego nuestra supervivencia como especie y la supervivencia del planeta.
\end{abstract}

Palabras-clave: espiritualidade; cualidad humana; ateísmo; laicidade; religión; antropologia; epistemología.

\section{Resumo}

O objetivo deste artigo é encontrar a relação entre a espiritualidade laica e a espiritualidade ateia para conduzir-nos ao que parece ser a única espiritualidade viável na sociedade do conhecimento. Nós analisamos textos de personalidades de referência de ambas as espiritualidades, como Feuerbach, Marx, Nietzsche ou Sponville Comte, entre outros. Observamos especificamente alguns dos elementos essenciais de uma espiritualidade ateísta: espírito crítico e racionalidade, centralidade e suficiência do ser humano e sua libertação da submissão e exploração, e uma vontade, sem limites, em vez de preguiça. No entanto, o objetivo principal é destacar que há um cultivo da dimensão absoluta da realidade além das tradições religiosas e que esse cultivo nas sociedades de mudança contínua requer como propõe Corbí, uma nova antropologia, de um animal que fala com duplo acesso à realidade; Apontamos também para a existência de uma nova epistemologia, além da mítica dos paradigmas anteriores que permite o uso meramente livre e simbólico das sabedorias da humanidade. Está em jogo a nossa sobrevivência como espécie e a sobrevivência do planeta.

Palavras-chave: espiritualidade; qualidade humana; secularismo; religião; antropologia; epistemologia.

\begin{abstract}
This article aims to find out the relation between secular and atheistic spiritualties underlining the only one that seems to be able to suit the knowledge society. We analyze several texts of main classical personalities of both spiritualities, such as Feuerbach, Marx, Nietzsche and Comte Sponville, among others. Some of the essential elements of an atheistic spirituality are specifically discussed: critical spirit and rationality, centrality and sufficiency of human beings and their release from submission and exploitation, and a will without limits instead of laziness. However, the main objective is to highlight that there is a culture of absolute dimension of reality beyond the religious traditions. We also intend to point out that culture, in changing societies, requires, as Corbí suggests, a new anthropology, of an animal who talks, with a dual access to reality. We also point to the existence of a new epistemology, beyond the previous mythical paradigms, allowing the merely free and symbolic use of mankind wisdoms. Finally, it is a question of survival of humankind and of its environment.
\end{abstract}

Keywords: spirituality; human quality; atheism; secularismo; religion; anthropology; epistemology.

Artigo recebido em 29 de junho de 2014 e aprovado em 18 de setembro de 2014.

* Doutor em Teologia. Professor e pesquisador do Centro de Estudios de las Tradiciones de Sabiduría (Barcelona). Diretor da Asociación UNESCO para el Diálogo Interreligioso. País de origem: Espanha. E-mail: f.torradeflot@cetr.net. 


\section{Introducción}

La espiritualidad es distinta de la religión pero está relacionada con ella. La verdad es que los profetas de la secularización han tenido que rectificar sus previsiones porque ni la religiosidad ni la espiritualidad han desaparecido. En una sociedad cada vez más cambiante parece que la religión tal como la conocemos, a diferencia de la espiritualidad, tiene sus días contados, pero es necesario saber qué tipo de espiritualidad es posible y si la espiritualidad laica y atea son una respuesta válida y en qué medida.

\section{La equívoca polisemia de los términos}

¿Qué significa espiritualidad? ¿Qué significa ateísmo? Ambos términos son tan polisémicos que generan y seguirán suscitando una cierta confusión. La inquietud y la búsqueda espiritual son una invariante humana que ha producido siempre una gran y compleja diversidad ${ }^{1}$. Por un lado, espiritualidad es una palabra que ha sido un patrimonio prácticamente exclusivo de las tradiciones religiosas, sobretodo de las abrahámicas y, entre éstas, especialmente de la cristiana. Incluso dentro de la tradición cristiana ha abundado más entre los católicos, especialmente en sus círculos monásticos y conventuales, lejos de los colectivos laicales, a pesar del relativamente reciente uso degradado de la palabra entre los nuevos movimientos eclesiales de base -con amplio protagonismo laico-. El cristianismo protestante ha visto mayoritariamente con reticencias la espirirualidad por expresar, a su parecer, más bien el esfuerzo prometeico y poner en cuestión el papel decisivo de la gracia divina para la salvación. La ortodoxia cristiana ha resrevado un papel importante a la espiritualidad a través del hesicasmo pero la verdad es que tradicionalmente ha quedado también muy restringida a los ámbitos monacales.

\footnotetext{
1 “La búsqueda espiritual es un universal enteramente compatible con la diversidad que es inevitablemente su resultado" (TORRANCE, 2006, p. 10).
} 
Además se ha generalizado mucho el uso del término espiritualidad para rehuir los excesivos inconvenientes e hipotecas históricas y sociales del término "religión". Parece, en estos casos, que usar el término "espiritualidad" es una palabra refugio, menos excluyente y que genera menos estereotipos y prejuicios, que por supuesto dan pie a anticuerpos, los principales obstáculos de la misión o, según como se mire, de la propaganda y la expansión proselitista religiosa. Este uso, según algunos sectores laicistas, sive de coartada y limpia la cara de la religión, lo cual despierta suspicacias y desconfianza.

Sin embargo, en los últimos cien años, especialmente con el crecimiento y consolidación del individualismo expresivo, se ha ido generando una cultura de la autenticidad -muy relacionada con el pluralismo-, según la cual es más importante el sentimiento que la doctrina. De acuerdo con esta cultura, lo espiritual ya no está ligado intrínsecamente a la religión (TAYLOR, 2007, p. 473-475, 489-490). Esta liberación y este cambio estan afectando claramente al lugar de la religión en el espacio público y a las formas móviles e incluso innovadoras de la religiosidad. La experiencia directa de lo sagrado es más valorada, así como lo es la búsqueda personal (TAYLOR, 2007, p. 506-508). Además la sociedad de conocimiento hace prácticamente inviable la religión tradicional (CORBÍ, 2007, p. 200-210).

Por otro lado, el ateísmo, al menos el tradicional, ha sido casi siempre identificado con una convicción, postura o actitud básicamente de cariz materialista, lo cual lo haría, al menos a primera vista, prácticamente contrario e incompatible con la espiritualidad. Este materialismo se convirtió en el pasado reciente en un tema de sentido común, especialmente en las sociedades "avanzadas" o "desarrolladas" (TAYLOR, 2007, p. 366). La espiritualidad era percibida como un obstáculo al humanismo. De hecho, el mismo deísmo, que rechazaba la intervención caprichosa e injusta de Dios en la historia, fue conduciendo poco a poco hacia un humanismo exclusivo, totalmente autónomo y en el cual el poder procede de la naturaleza, no de Dios, porque se han descubierto las fuentes intrahumanas de bondad. Esta fue la carta de la increencia moderna (TAYLOR, 2007, p. 221. 234. 245. 256-257. 569.). Algunas de las personalidades 
inspiradoras de este humanismo exclusivo fueron Rousseau, Kant, Darwin, Carlyle o Russell, entre otros. El humanismo exclusivo ha sido responsable en gran medida de algo de lo que se han beneficiado, con posterioridad, las mismas creencias: la libertad de creencia (TAYLOR, 2007, p. 260)². Una libertad de creencia que, aunque a menudo se silencie, es claramente contraria o "perjudicial”, por lo menos en sus consecuencias sociológicas, a los intereses de la ortodoxia religiosa (TAYLOR, 2007, p. 302. 305). Es cierto que el desarrollo de la secularidad contemporánea ha ido generando una ética de la autenticidad y del individualismo que es calificada por Taylor de "espiritual supernova, una especie de pluralismo galopante en el plano espiritual" (TAYLOR, 2007, p. 300. 307). El pluralismo es más que una simple convivencia de los credos y convicciones, es sobre todo la oportunidad de poder optar (TAYLOR, 2007, p. 304). Es también interesante reconocer la importancia del cambio científico más por sus consecuencias en el imaginario colectivo que por otras razones. Es decir, con la desaparición del creacionismo, se pierde el miedo a la naturaleza. Ya el propio deísmo de personalidades como Henry Thoreau había desembocado en un claro antropocentrismo (TAYLOR, 2007, p. 325-.326. 339-342).

En el siglo XIX se observa una línea de pensamiento y sensibilidad surgida entre no creyentes y que representa un cierto ataque desde dentro contra valores clave de la Ilustración. Taylor le llama la "revuelta inmanente" (TAYLOR, 2007, p. 723-724), sobre todo por su reacción ante la primacía de la vida y a causa del redescubrimiento de la centralidad de la muerte en la vida humana. Pero en pleno siglo XX hacia finales de la década de los 80, si no antes, se empieza a observar en círculos tradicionalmente escépticos o ateos, una cierta valoración de la dimensión espiritual del ser humano des de las filas ateas más ilustradas e incluso des de las realidades sociales más dinámicas y creativas, algunas de ellas cercanas a los cambios sociológicos resultantes de una secularización que, si bien ha afectado sensiblemente a las grandes tradiciones religiosas, ha supuesto también un

\footnotetext{
${ }^{2}$ Sobre la relación entre libertad de creencia, derechos humanos y diálogo interreligioso ver TORRADEFLOT, 2010, p. 562-566 y TORRADEFLOT, 2002.
} 
desplazamiento del hecho religioso que ha generado nuevas e inesperadas formas de religiosidad y espiritualidad, lejos de las prospectivas que anunciaban la desaparición definitiva de la religión. Es cierto, que según la definición y los desplazamientos de la religión, la secularización es un fenómeno más o menos amplio (TAYLOR, 2007, p. 427), lo que siempre ha conllevado una cierta perplejidad en los planteamientos maniqueos y tradicionalmente enfrentados entre teísmo y ateísmo. Estos esquemas llenos de prejucios y estereotipos prefieren simplificar y generalizar para poder apuntar y dirigir mejor sus habitualmente acaloradas diatribas.

\section{Las tradiciones religiosas cada vez más laicas y libres}

Nos interesa ahora considerar la laicidad en su significado de no clerical, no institucional, porque conlleva la relativización de cualquier tipo de mediación. Mediación y sumisión han ido históricamente de la mano. Pero la espiritualidad no necesita la mediación. En la línea de lo que el mismo Voltaire comenta a propósito de una conversación que tuvo con un cuáquero: "Entonces me abrumó con citas de la Escritura que demostraban, según él, que no hay cristianismo sin una revelación inmediata." (VOLTAIRE, 1988, p. 43). La no mediación entre el ser humano y la divinidad la plantearon en la historia espiritual del cristianismo diversos autores, tantos que no podemos ahora abordarlos. Baste decir que la mayoría de ellos eran místicos, que la propia reforma protestante se inspira en la tendencia a rechazar parcialmente la mediación (Lutero) y que sus más radicales seguidores, los anabaptistas como, por ejemplo, Thomas Müntzer, subrayan la importancia de relativizar la mediación absolutamente, incluso la de la Palabra externa, la Bíblia (MÜNTZER, 1989, p. 113), y la necesidad de escuchar la "palabra interior en la profundidad de las almas", porque el ser humano es "residencia de Dios y del Espíritu Santo" (MÜNTZER, 1989, p. 66-67)3. En este contexto histórico se denuncia claramente la hipocresía de la pretendida mediación (MÜNTZER, 1989,

\footnotetext{
${ }^{3}$ Para Müntzer es necesaria una purificación, una desnudez del corazón , una "cruz", para poder aceptar esta revelación interior que se da sin mediación (MÜNTZER, 1989, p. 124).
} 
p. 128). Eugen Drewermann considera que lo específico de toda religión es la inmediatez de Dios (DREWERMANN, 1997, p. 95-96)4.

Las propias tradiciones religiosas mayoritarias y clásicas han experimentado en los últimos tiempos un creciente interés por la espiritualidad que ha hecho reaparecer o surgir por primera vez algunas corrientes y maestros de espíritu que valoran más la experiencia directa de la Realidad, Divinidad o Dios, que la formulación de las creencias, doctrinas o dogmas, que tan esenciales eran para las instituciones religiosas en períodos social y políticamente anteriores. Ese relativismo light ante las formulaciones ha permitido que se llegue a cuestionar la imagen de Dios y la relación con él, resultando en diversos tipos de aproximación de estas tradiciones a ciertos planteamientos propios o cercanos al ateísmo. En este sentido, uno de los teólogos más emblemáticos, por llegar a considerar a los maestros de la sospecha del ateísmo como auténticos profetas purificadores del cristianismo, es Eberhard Jüngel en su obra Dios como misterio del mundo (JÜNGEL, 1984). La teología valora el discurso ateo como lugar teológico privilegiado además de la Escritura y la Tradición.

La clara liberalización y despatrimonialización del hecho religioso, que ha conllevado y conlleva continuas transformaciones e innovaciones en sus formas de expresión y de organización, ha cedido la primacía a las personas por encima de los colectivos y a las minorías por encima de las mayorías, generalmente más resistentes a los cambios $\mathrm{y}$, por tanto, más anquilosadas y decadentes (TORRADEFLOT, 2002, p. 38-47). El auténtico desafío para el no creyente, donde se pone a prueba su auténtica libertad, es la referencia transcendente que queda reflejada de una manera especial en el valor de la sensibilidad espiritual no teísta o atea (TAYLOR, 2007, p. 607). Cuando este desafío se asume, se trata de un humanismo exclusivo más positivo, capaz de combinar espíritu y humanismo y que no cae en la intolerancia ni en la violencia antitranscendente (TAYLOR, 2007, p. 640-642). La espiritualidad secular pone su acento sobretodo en la benevolencia

\footnotetext{
${ }^{4}$ Para Drewermann Dios habla desde dentro del ser humano (DREWERMANN, 1997, p. 131. 166).
} 
(TAYLOR, 2007, p. 679-680). Por eso algunos, como Taylor, afirman que el ateísmo tiene más fuerza ética -acción desinteresada- que epistemológica (2007, p. 701-702).

Taylor propone un relativismo suave y tolerancia entre creencias $\mathrm{y}$ convicciones (TAYLOR, 2007, p. 484).. De hecho, en la actualidad, creyentes y no creyentes comparten un marco de inmanencia que los fragiliza a ambos (TAYLOR, 2007, p. 594-595). Lamentablemente demasiado a menudo ateos y religiosos ortodoxos y fundamentalistas rechazan la religión humana del pasado (TAYLOR, 2007, p. 770), que no es distinta de lo que Johan Galtung considera la "soft religion" (GALTUNG, 1995, p. 57-63). Y esta falta de tolerancia supone una postura exclusivista que rechaza la libertad personal y comunitaria y pone en peligro la convivencia, la paz y la supervivencia de la humanidad.

\section{Una nueva base antropológica y epistemológica para la espiritualidad}

La espiritualidad es la dimensión sutil de la existencia, la dimensión absoluta de la realidad. Pero, como hemos sugerido más arriba, una cosa es la espiritualidad de los laicos resultante de la secularización del hecho religioso en, por ejemplo, comunidades tan clericales como la católica y otra, aparentemente bien distinta, es la espiritualidad laica resultante de la tradición agnóstica o incluso atea. Pero las cosas no son tan claras. Sobre todo porque se está en medio de un proceso dinámico constantemente cambiante, en ocasiones incluso convergente, y que hace innecesario, y tal vez imposible, separar y distinguir con rigor analítico y académico los conceptos que pretenden definir esta realidad fluida y viva. Ello es especialmente comprensible cuando se percibe que espirituales ateos no se inquietan ni incomodan con la espiritualidad laica surgida y separada de la espiritualidad clerical y viceversa cuando espirituales laicos de tradición religiosa valoran, simpatizan e incluso incorporan aportaciones hechas desde el ámbito más propio y particular de la espiritualidad atea, como hemos apuntado más arriba con la obra de Eberhard Jüngel. Es más que probable que una secularización surgida de 
la espiritualidad cristiana auténtica y libre esté en los fundamentos de la espiritualidad atea (VATTIMO, 1996, p. 41-42) y que ésta pueda liberar aquella de sus impurezas.

La tradición laica cristiana surge, entre otras razones, del desencanto y de la saturación de un cristianismo monástico y clerical que durante siglos se fue consolidando como un monopolio y convirtiendo en claramente hegemónico y que había desembocado en un menosprecio del mundo y del ser humano (DELUMEAU, 1983, p. 15-43). Determinado reformismo cristiano medieval y moderno supuso ya una cierta reacción ante y contra esta predominancia clerical casi exclusiva y frente al papel pretendidamente mediador del profesional de la religión, del que vive y se dedica exclusivamente a la dimensión relativa y a la función básicamente social de la religión, relegando al resto de los creyentes a un papel de obediencia y de sumisión estrictas. Personalmente encuentro que la máxima expresión de esta corriente la encontramos en la actualidad en la espiritualidad cuáquera y unitarista. Ambas aceptan ya sin problemas la presencia de ateos entre sus filas, pero eso sí, ateos espirituales.

La espiritualidad atea es la de los ateos hijos de la ilustración de matriz judeocristiana que, en gran medida, fue posible también gracias a la espiritualidad laica surgida como reacción frente al cristianismo clerical y monacal. No es extraño que hoy parezca ya evidente que, en ocasiones, se da entre los ateos la aceptación de la existencia de alguna realidad absoluta o última que no sea personal. Incluso aunque se niegue la existencia de un dios personal, ello puede significar algún tipo de espiritualidad. Es lo que intentaremos mostrar.

En primer lugar mostraré la espiritualidad de la mayoría de los maestros de la sospecha, todos ellos claramente ateos. Más adelante veré ejemplos de otro tipo de ateísmo más "científico". En todos los casos desvelaré una apertura y sensibilidad hacia una dimensión absoluta de la realidad que forma parte de la naturaleza humana. No consideraré aquí, más que tangencialmente y en función 
siempre de la espiritualidad atea, la espiritualidad cristiana laica alternativa a la espiritualidad cristiana clerical y monacal. Tampoco dedicaré tiempo a las espiritualidades laicas de las diversas tradiciones religiosas, que, por supuesto, existen y tienen una larga tradición en el seno de cada confesión concreta.

Sin embargo la laicidad de una espiritualidad no la produce simplemente su ruptura o tensión con sus orígenes clericales o su negación de la existencia de un dios personal, ni la suma de los dos. La espiritualidad laica es por encima de todo, en sentido más amplio y radical, esa espiritualidad sin creencias y sin instituciones religiosas, esa espiritualidad no sometida a formulaciones estáticas ni a estructuras sociales fijas. Sería un error pensar que la opción por la ausencia de formulaciones dogmáticas y de instituciones estáticas es fruto sobre todo de la libre decisión de las personas. Aun sin negar la libertad personal queda bastante claro que esta opción es inevitable dadas las condiciones culturales de la sociedad de conocimiento y no es fruto de un refinamiento espiritual superior al de nuestros antepasados como algunos evolucionistas espirituales amantes de la antroposofía estarían tentados de afirmar. Pero no es una mala noticia sino "un gran don para la humanidad" por ser "una espiritualidad sin ambigüedades", una "espiritualidad creativa y heredera de la rica y diversa tradición espiritual de toda la humanidad.” Para Corbí esta nueva forma de cultivo de la espiritualidad resulta ardua, sutil y difícil porque nos deja sin asideros, pero al mismo tiempo permite construir los propios proyectos axiológicos colectivos que hacen posible sobrevivir en una sociedad de cambio contínuo (CORBÍ, 2007, p. 222-227. 344-346).

La nueva antropología de esta espiritualidad sin creencias no es una antropología de cuerpo-espíritu, como en los antiguos paradigmas de cazadoresrecolectores o de culturas agrarias; ni una antropología de animal racional, como en el paradigma industrial; sino una antropología de animal que habla, de la necesidad de un viviente, de un animal que para sobrevivir se adapta -y que así suple su indefinición genética- a los cambios del medio a través del lenguaje. El lenguaje le facilita el doble acceso a lo real, a su dimensión relativa, a la realidad como estructura de necesidades, y a su dimensión absoluta o no relativa (CORBÍ, 
2013, p. 81-85)5. De hecho, el cultivo de la espiritualidad es el cultivo de ambas dimensiones de una manera no dual (CORBÍ, 2007, p. 257-294).

El cultivo de la espiritualidad o de la cualidad humana profunda, que Corbí define como el cultivo de la dimensión no relativa de la experiencia, es el cultivo del interés, desapego y silenciamiento (IDS) así como de la indagación, comunicación y servicio (ICS) tal y como se ha producido en las tradiciones y que ahora, en una sociedad en tránsito o en una sociedad del conocimiento, sólo podemos cultivar sin el bagaje coyuntural de creencias y de sumisión que, dada la necesaria función social de las religiones en otros paradigmas, antaño parecían inseparables (CORBÍ, 2013 (2), p. 227-300).

Pero acceder al cultivo de la cualidad humana profunda de nuestros antepasados requiere una epistemología no mítica o axiológica que no identifique la expresión o la descripción de la realidad con la misma realidad y que permita una lectura puramente simbólica de los símbolos y mitos tradicionales alejada de la sumisión a los sistemas de creencias. Los mitos serán sólo sistemas simbólicos complejos afirmaciones, afirmaciones apofáticas o metáforas de la dimensión absoluta de la realidad y así podrán ser leídos y aprovechados por hombres y mujeres de sociedades radicalmente distintas de las que los conformaron (CORBÍ, 2007, p. 152-155. 219-222. 235-241).

\section{Preámbulos de una espiritualidad atea: espíritu crítico y racionalidad}

No pretendo enzarzarme en una discusión imaginaria con polemistas, apologéticos o no, que cuestionen la idea de espiritualidad atea. Ni tan siquiera siento un apego especial hacia la expresión que me parece simplemente una manera de entendernos. Simplemente quisiera apuntar algunos elementos que suscitan en mí el reconocimiento de valiosos prámbulos, o tal vez indicios, de una

\footnotetext{
${ }^{5}$ Cfr. CORBÍ, 2007, p. 257-294.
} 
realidad espiritual o de cualidad humana profunda en el seno de las filas tradicionalmente agnósticas o ateas. No se trata, ni mucho menos, de convertir esto en una nueva o inconsciente -en el sentido rahneriano de "anónima"- religión sin Dios. Sólo pretendo mostrar y compartir el gusto por algunos platos suculentos de esta espiritualidad atea, por llamarla de alguna manera. Provar antes de juzgar.

Para ello procuraré mostrar algunos textos o pasajes de los grandes referentes de la espiritualidad atea. Uno de los indicios más genuino de la espiritualidad laica o atea -este adjetivo pone el acento en la negación del Dios personal- es su actitud profética, de crítica y especialmente de denuncia, del propio interés bajo la cobertura del discurso de la religiosidad del amor. Esta denuncia pretende ser fiel a la misma y legítima autenticidad primigenia de los orígenes de un fenómeno espiritual, pero obviamente es demoledora frente a las malformaciones históricas que sin embargo han surgido de su prole. Además del análisis y la denuncia, la solidaridad con las ignorantes e inocentes víctimas que sufren el engaño es claramente una expresión de cualidad humana (HOBBES, 2009, p. 56). La importancia de la racionalidad es fundamental para evitar que el fervor o el rigor disfracen la superstición de falsa cualidad humana. La razón es un instrumento privilegiado de cultivo de la espiritualidad, una de las dimensiones de la importancia del trabajo mental en el camino espiritual. Cuantas espiritualidades ilusorias, vanidosas o interesadas han quedado completamente desautorizadas por el mínimo sentido común (HUME, 2009, p. 80). La espiritualidad atea es una espiritualidad crítica donde la razón no sólo no es anulada sino que juega un papel básico. Pero no se trata de una racionalidad cualquiera ni "diabólica", sino inspirada en la benevolencia y la humildad y que hace que la virtud sea agradable y la superstición “odiosa y onerosa” (HUME, 2009, p. 70-72).

El espíritu crítico no es negativo. Sirve para eliminar con honestidad la falsedad, aquello que en conciencia no se reconoce como verdadero. A menudo el ateísmo ha sido caricaturizado por sus enemigos como deshonesto y falso. Como todo fenómeno de la historia de las ideas, ciertamente habrá de todo entre sus partidarios, pero en general atribuirle como bloque deshonestidad o maldad es reflejo de un 
prejuicio, de un estereotipo simplista y erróneo no muy distinto del que proyecta a veces el mismo ateísmo sobre las religiones.

\section{La centralidad y suficiencia del ser humano y su liberación de la sumisión y de la explotación: Feuerbach y Marx}

Para el padre de los maestros de la sospecha, Ludwig Feuerbach (1804-1872), que era teólogo y filósofo, lo verdadero en la religión es santo porque ésta, la religión, es la primera conciencia que el hombre tiene de sí mismo y el amor al ser humano debe liberarse de la motivación heteronónoma: "Homo homini Deus est; éste es el primer principio práctico, éste es el momento crítico de la historia del mundo.” (FEUERBACH, 1995, p. 28).

El antropoteísmo es la auténtica religión, la supresión de la escisión entre corazón y cabeza porque el ser humano se da cuenta íntegramente -por un corazón convertido en entendimiento- que es Dios:

El antropoteísmo es el corazón convertido en entendimiento; sólo le dice razonablemente a la cabeza lo que el corazón le cuenta a su manera. La religión sólo es afecto, sentimiento, corazón, amor, es decir, negación, disolución de Dios en el hombre. Por eso la nueva filosofía, en tanto que negación de la teología, la cual niega la verdad del afecto religioso, es la posición de la religión. El antropoteísmo es la religión autoconsciente, la religión que se comprende a sí misma. La teología, por el contrario, niega a la religión bajo la apariencia de ponerla. (FEUERBACH, 1984, p., 35).

El hombre es lo más importante de la religión. Hablar de Dios es hablar de él, de él en su plenitud, en su ideal. Por eso amar al hombre debe ser gratis, por el hombre mismo, no por Dios. Si ello es así, seguro que nadie tendrá la tentación de usar al hombre como medio para el fin Dios - "sueño" de la moral kantiana-; nadie tendrá la terrible tentación, a juzgar por sus bárbaras consecuencias históricas, de instrumentalizar al ser humano. La espiritualidad atea opta decididamente por la primacía de lo sensible, del ser humano, por su centralidad. Esta es una característica 
que desde Feuerbach será ya común a la mayoría de sus autores de referencia. Feuerbach, que era un hegueliano de izquierda, lleva la religión a sus fundamentos antropológicos. La religión revela los tesoros escondidos del ser humano. Es importante subrayar que Feuerbach fue muy influenciado por la publicación del libro Vida de Jesús (1835) de Friedrich Strauss que no consideraba históricamente verdaderos sino míticos los Evangelios. Era ya un antecesor del reconocimiento de la epistemología mítica de los textos religiosos, punto en el cual hoy convergen muchas espiritualidades sean confesionales o no.

El ateísmo no rechaza el patrimonio de sabiduría de las tradiciones religiosas. De hecho esta es la profunda convicción de Feuerbach. Gracias a las religiones el ser humano ha podido pensar lo infinito, que es él mismo. La sabiduría de las religiones dice mucho sobre el ser humano, como nadie antes hubiera imaginado poder decir. De hecho lo infinito ha transformado a la propia consciencia que es universal. Esta consciencia, este ser humano universal, es razón -pensamiento-, voluntad -energía del carácter- y corazón -amor-. Éstas son sus fuerzas absolutas.

La espiritualidad atea se revela aquí integradora, unificadora del ser humano (FEUERBACH, 1995, p. 54-55). Su voluntad es de no escindir al ser humano, de respetar y cuidar la personalidad del ser humano en su integralidad. Se quiere superar la dualidad entre vida y verdad, entre objeto y sujeto, entre existencia y esencia que ha hecho que la religión margine, relegue o anule sin piedad lo material y lo sensible, especialmente el cuerpo. La espiritualidad atea no puede aceptar el rechazo del cuerpo o de la materia y su actitud es justamente la de buscar una harmonía integradora de las capacidades del ser humano (FEUERBACH, 1979, p. $303 \cdot 345)$.

Mirando al ser humano en toda su magnitud se reconoce la dimensión absoluta. Esta es la gran aportación de la espiritualidad atea. No hace falta mirar fuera, no hay que amar, pensar o querer al ser humano por algo externo a él, sino que el ser humano existe para sí mismo con todo su corazón, con toda su mente y todo su 
ser. Se trata del "Shema Israel" del ateísmo6. El humanismo resultante es fruto de esta opción radical.

El pensamiento - el de sabiduría- de la humanidad a lo largo de la historia es un patrimonio inmenso, admirable e inconmensurable. Feuerbach lo considera "su espíritu, su alma”. De hecho afirma que Dios es el "tesoro oculto", el "interior revelado" o expresado del ser humano, sus "pensamientos más íntimos”, sus “secretos de amor". No hace falta buscarlo fuera de sí mismo (FEUERBACH, 1995, P. 64-65).

Tal vez Dios no exista como ser separado pero sí que existe como expresión de la dimensión valiosa, espiritual y oculta del ser humano, de su cualidad humana profunda. Lamentablemente lo que habitualmente se entiende por religión no se da cuenta de ello y, por, ello es como es y hace que el ser humano busque fuera -se aliene- lo que tiene dentro de sí. Desde ahora no hace falta perder el tiempo fuera, hay que mirar - pensar y amar- dentro. Algunos autores como Feurebach otorgan, ni que sólo sea temporalmente o estratégicamente, un doble sentido al término "religión". Uno es claramente peyorativo y debe ser superado, otro es claramente nuevo y liberador. Con el tiempo, tal vez por los avatares de la contienda filosófica, el sentido innovador suele ceder y se termina por abandonar el término en manos del sentido "viejo", claramente institucional y tradicional.

Algunos pensadores, como Karl Marx, han llegado a afirmar que la religión, que es ja judeocristiana institucional, es una causa importante del sufrimiento del ser humano, de su desdicha y de su espíritu vacío. Así pues la no religión deviene el camino de la dicha y del espíritu. Se trata, pues, de una espiritualidad de la dicha que se cultiva a partir de la denuncia, el desenmascaramiento y la revuelta contra quienes la impiden. Por ello el ateísmo humanista se hace con Marx decididamente sociopolítico y económico al denunciar sobretodo a los que se aprovechan de la

\footnotetext{
6 “Amarás a Yahveh tu Dios con todo tu corazón, con toda tu alma y con toda tu fuerza” (Deuteronomio, 6, 5). Feuerbach sustituye a Yahveh por el ser humano.
} 
alienación básica del ser humano, que es la separación forzada de los resultados de su trabajo. Marx fue de los primeros en poner en evidencia de qué manera la religión estaba al servicio del poder político y económico y cómo había que dar la vuelta a la situación. Por eso su ateísmo es revolucionario y sigue pleno de vigencia a pesar del claro fracaso de las concreciones ideológicas históricas de su pensamiento. La denuncia y transformación del sufrimiento son una expresión maravillosa de la espiritualidad marxista que ha sido difícilmente apreciable desde la marabunta política de los enquistados bloques militares de la posguerra7. Sólo la teología de la liberación ha sido capaz de valorarlo con cierta transparencia. La espiritualidad marxista es una construcción, una expresión, un aroma natural de la humanidad que se revela ante la miseria de la humanidad, que no acepta que su mundo haya sido invertido (KÜNG, 1979, p. 321).

De hecho el ser humano ha vivido subyugado y esclavizado por los dioses durante siglos, porque son éstos los que han servido de justificación para la alienación económica. Aquí Marx se refiere a la tradicional función de la religión de cohesión, probablemente imprescindible para la supervivencia de la especie y ejercida eficazmente durante los paradigmas preindustriales. En un período de consolidación industrial, la crítica de la religión es por ello la madre de todas las críticas. Por ello Marx, siguiendo en ello a Feuerbach, considera la autocociencia humana la suprema divinidad y la filosofía la protagonista prometeica de esta liberación ${ }^{8}$. El valor de esta tradición espiritual es reconocer que el hombre puede y debe realizar una tarea divina y que no puede ni debe excusarse en dioses para dejar de hacer lo que tiene que hacer. Esta fe en la praxis humana como fuerza de transformación y cambio es la singular aportación de Marx en relación al humanismo feuerbachiano. La espiritualidad humana debe ser testada en la praxis, en su capacidad de transformar el mundo para la liberación y el bienestar del ser humano.

\footnotetext{
${ }^{7}$ Es importante juzgar la voluntad de transformación de la realidad por sus manifestaciones más virtuosas no por sus debilidades o patologías: "La força d'una ètica es jutja pel comportament dels sants, no pel dels ignorants, cuius deus venter est." (ECO, 1997, p. 54).

8 "La filosofía no lo oculta. Hace suya la profesión de fe de Prometeo: "iEn una palabra, odio a todos los dioses!". Y opone esta divisa a todos los dioses del cielo y de la tierra que no reconozcan como suprema divinidad a la autoconciencia humana. Esta no tolera rival". (MARX, 1971, p. 7, Prefacio).
} 
El político socialista de la transición democrática española, filósofo marxista y teórico del agnosticismo Tierno Galván reivindica que los agnósticos "no han perdido lo absoluto" sino que lo identifican con lo único que tienen de verdad que es el mundo. Acepta lo divino entendido como "fundamento finito de la finitud", como lo vulnerable porque "lo divino de la finitud es la finitud misma". Aceptar la finitud sin transformarla en Dios, aceptándola como es, esa es la divinidad de lo finito (TIERNO GALVÁN, 1982, p. 102-107). La aceptación consciente de la finitud como lo único existente y de que no hay trascendencia salva de cualquier alienación, de cualquier alejamiento del mudo y obliga a comprometerse en la tarea de perfeccionar la historia. De esta manera la espiritualidad, como proponía Marx, debe encarnarse en la transformación de la historia (TIERNO GALVÁN, 1982, p. 127).

No hay duda de que el materialismo de Feuerbach influyó en lo que después fueron el materialismo dialéctico y el materialismo histórico marxistas. Sin embargo quisiera subrayar, entre las fuentes del marxismo con mayor interés espiritual, el socialismo utópico de Owen y Saint-Simon, influidos a su vez por Rousseau, el cooperativismo, el harmonista (New Harmony) George Rapp y los separatistas de la Iglesia de Inglaterra. La espiritualidad cristiana laica aparece como la buena "religión", como una predisposición o un fundamento del pensamiento de Marx.

\section{Voluntad ante la miseria de una humanidad que tiene pereza de ser divina: Nietzsche.}

El ateísmo de Friedrich Nietzsche es una expresión angustiada de la ausencia de la realidad absoluta. El filólogo clásico hijo de un pastor luterano vive a sus 25 años su relación con el absoluto a partir de su desconocimiento y de la 
atracción que suscita en él, una atracción intelectual pero también afectiva9:

La nostalgia del ateo le lleva a una prospectiva de Dios (KÜNG, 1979, p. 553), pero de un Dios sin rostro religioso. Para Nietzsche el ateísmo es la liberación del sentimiento de culpa milenario que ha sumido en una decadencia a la humanidad, una especie de segunda inocencia (NIETZSCHE, 1990, p. 103-104).

En el segundo período de la producción filosófica de Nietzsche (1876-1882), se presenta el combate contra la “decadencia” expresada en la moral y la religión sobretodo la cristiana-. Nietzsche reprocha al cristianismo su hipocresía, su papel esencial en el debilitamiento del ser humano y su enquistamiento en reliquias dogmáticas increíbles de un mundo ilusorio de representaciones con apariencia de verdad. Esta es la gran conspiración contra Dios, al que los hombres hemos asesinado. Nietzsche ejerce aquí la función profética de denuncia de la falsa religión, falsa por incoherente consigo misma. La actitud es parecida a la de otros maestros de la sospecha, pero Nietzsche ya apunta que la experiencia espiritual no debe ser necesariamente una opción a favor de los débiles sino una experiencia de poder.

El ser humano tiene un inmenso poder en su interior. Especialmente relevante es la relación que Nietzsche establece, en su autobiografía, entre experiencia espiritual y proceso creativo. Reconoce la efabilidad de la realidad en su simplicidad, su transparencia y luminosidad. La espiritualidad no religiosa establece a menudo una estrecha relación entre experiencia del absoluto y experiencia estética:

El concepto de revelación, en el sentido de que de repente, con indecible seguridad y finura, se deja ver, se deja oír algo, algo que le conmueve y trastorna a uno en lo más hondo, describe sencillamente la realidad de los hechos. Se oye, no se busca; se toma, no se pregunta quién es el que la da; como un rayo refulge un pensamiento, con necesidad, sin vacilación en la forma -yo no he tenido jamás que elegir. Un éxtasis cuya enorme tensión

\footnotetext{
${ }^{9}$ NIETZSCHE, F., Poema "Al Dios Ignoto" (Demunbekannten Gott), citado en GIRARDI, 1967-1970, v. 1, p., 265. Esta misma atracción se percibe en el poema "el lamento de Ariadna" donde habla de su "último compañero", de su "dios desconocido". ¿A quien se refería Nietzsche en boca de Ariadna? (Poema "El lamento de Ariadna" en el último libro de Nietzsche, Ditirambos de Dionisio, citado en KÜNG, 1979, p. 540-542).
} 
se desata a veces en un torrente de lágrimas, un éxtasis en el cual unas veces el paso se precipita involuntariamente y otras se torna lento; un completo estar-fuera-de-sí, con la clarísima consciencia de un sinnúmero de delicados temores y estremecimientos que llegan hasta los dedos de los pies; un abismo de felicidad, en que lo más doloroso y sombrío no actúa como antítesis, sino como algo condicionado, exigido, como un color necesario en medio de tal sobreabundancia de luz; un instinto de relaciones rítmicas, que abarca amplios espacios de formas -la longitud, la necesidad de un ritmo amplio son casi la medida de la violencia de la inspiración, una especie de contrapeso a su presión y a su tensión.... Todo acontece de manera sumamente involuntaria, pero como en una tormenta de sentimiento de libertad, de incondicionalidad, de poder, de divinidad...La involuntariedad de la imagen, del símbolo, es lo más digno de atención; no se tiene ya concepto alguno; lo que es imagen, lo que es símbolo, todo se ofrece como la expresión más cercana, más exacta, más sencilla. Parece en realidad, para recordar una frase de Zaratustra, como si las cosas mismas se acercasen y se ofreciesen para símbolo". (NIETZSCHE, 1989, p. 97-98).

Nietzsche tiene la clara percepción que su papel es desvelar, cual profeta (Zaratustra) inédito del fin de los tiempos o del inicio de los nuevos tiempos aunque sea en el seno de un eterno eterno-, la revelación de la radical novedad de lo cotidiano. Lo presente es lúcido y transparente como nunca antes. Se trata de una especie de "mística" de lo concreto que se acerca y dice a cada uno la no dualidad de la realidad, lo más benigno, con una sabiduría que, al ser de ahora, anorrea las del pasado (NIETZSCHE, 1989, p. 101-102).

La sensibilidad de Nietzsche exalta el valor de la vida, cansado como estuvo durante su torturada historia personal de una espiritualidad de la muerte. Aparece en determinados pasajes de su obra como un enamorado de la vida, del cuerpo y de la voluntad en contraste con la propuesta de las religiones, de la mayoría de ellas. Con el cristianismo, la espiritualidad había quedado reducida a la negación de la vida, a la voluntad de nada y había quedado al margen la voluntad de poder (NIETZSCHE, 1978, p. 43).

La espiritualidad es una experiencia real, de transformación de la realidad, no una "fe". En ello este autor no está lejos de Marx. En efecto, para el autor de Así habló Zaratustra, Jesús fue el único cristiano y el cristianismo, que en este pasaje es objeto de su admiración, es una praxis, un hacer, en lugar de una creencia; una 
praxis que constituye un ser distinto:

- Voy a volver atrás, voy a contar la auténtica historia del cristianismo. -Ya la palabra "cristianismo" es un malentendido-, en el fondo no ha habido más que un cristiano, y ése murió en la cruz. El "evangelio" murió en la cruz. Lo que a partir de ese instante se llama "evangelio" era ya la antítesis de lo que él había vivido: una "mala nueva", un disangelio. Es falso hasta el sinsentido ver en una "fe", en la fe, por ejemplo, en la redención por Cristo, el signo distintivo del cristiano: sólo la práctica cristiana, una vida tal como la vivió el que murió en la cruz, es cristiana... No un creer, sino un hacer, sobre todo un nohacer-muchas-cosas, un ser distinto. (NIETZSCHE, 1978, p. 69).

Su temperamento sume a Friedrich en una inmensa e irreversible soledad alimentada por la filosofía del gran solitario y filósofo del pesimismo vital Schopenhauer -según él el "primer ateo autónomo e insobornable" de Alemania-, que Küng califica de "otro gran ejemplo de la "religiosidad" atea moderna" (KÜNG, 1979, p. 497). Esta espiritualidad se mece, pues, con la negación y renuncia budista que ocupan el espacio de su fe infantil perdida. Lo importante aquí es destacar que Nietzsche presenta el dolor y el sufrimiento humano como un espacio de verdad universal, de experiencia profunda y radical de la realidad. En cambio el amor se presenta, en muchos casos, como la renuncia cobarde al dolor de la existencia real. Su testimonio espiritual es de una transparente honestidad con la vida tal y como él la experimentó, tal y como él la percibió, en su dureza radical. El que ama de verdad la vida y la realidad la reconoce tal como es sin disfrazarla (NIETZSCHE, 1978, p. 58-59).

Pero Nietzsche ejerce, de alguna manera, de teólogo cristiano crítico y laico. Denuncia la manipulación de la original pureza vitalista del fundador. Considera el cristianismo vital de Jesús como totalmente contrario al posterior cristianismo sacrificial de Pablo de Tarso. El dios de Pablo es un "crimen contra la vida”, no sólo un error. No tiene contacto con la realidad, ni con la sabiduría del mundo, ni con la ciencia; es una amenaza a la disciplina, pureza, aristocracia y libertad del espíritu (NIETZSCHE, 1978, p. 82). 
La teología, la de los teólogos, es contraria a la experiencia, a la vida. Jesús ha suprimido el concepto de culpa y de deuda que necesita una redención y así suprime la separación entre Dios y el hombre, que ya están unidos. Esta unión o no dualidad es la buena noticia para el ser humano, no un privilegio de un ser divino (NIETZSCHE, 1978, p - 72). En contra del ateísmo inconsecuente de "físicos y fisiológos”, la espiritualidad atea es dura, no es fácil. No es frívola ni irresponsable. Eso es lo que pretende afirmar con la parábola del "hombre loco" que enciende una linterna una mañana y proclama la muerte de Dios. El ser humano no puede eludir su responsabilidad ante lo que ha hecho: matar a Dios. Asumir este hecho es el primer paso de la nueva época, de la divinización del ser humano. Este es el emotivo pasaje:

iDios ha muerto y nosotros somos quienes lo hemos matado! ¿Cómo nos consolaremos, nosotros, asesinos entre los asesinos? Lo que el mundo poseía de más sagrado y poderoso se ha desangrado bajo nuestro cuchillo. [...] ¿No estamos forzados a convertirnos en dioses, al menos para parecer dignos de los dioses? No hubo en el mundo acto más grandioso y las futuras generaciones serán, por este acto, parte de una historia más alta de lo que hasta el presente fue la historia. Aquí calló el loco y miró de nuevo a sus oyentes; ellos también callaron y le contemplaron con extrañeza. (NIETZSCHE, 2014, p. 125 ).

El dolor de Nietzsche ante este acto sólo puede ser curado por la responsabilidad del superhombre, del que lleva la luz y lo anuncia sin miedo a su soledad ni a su fracaso. Esta profunda responsabilidad no significa una pura constatación psicológica sino un hecho básico para su visión del ser humano y del mundo: es un vacío desolador. No es sólo un reflejo de la situación del ser humano abandonado a su sola suerte, sino más bien una toma de consciencia luminosa para propiciar un cambio radical de situación. Es un testimonio de fe en el ser humano, en su poder, en sus capacidades, pero la humanidad no está todavía preparada... Propone una “especie de espíritus” fuerte, salvada y redentora, capaz de abarcar los contrarios sin contradicción, con una "sublime maldad" y capaz de aceptar la responsabilidad de edificar de rescatar la realidad, de un cambio axiológico, de construir desde su cualidad humana un nuevo horizonte que devuelva "a la tierra y 
al hombre su esperanza (NIETZSCHE, 1990, p. 109-110). Nietzsche usa este lenguaje con una clara voluntad performativa, con ganas de hacer que las cosas sean distintas. El ser humano deberá todavía vencer muchos obstáculos que son inercias de su edad inmadura. Es cierto que su propuesta de superhombre desembocó en su locura personal no exenta de megalomanía, pero su mensaje y testimonio de vida, llenos de indicios de espiritualidad, son un auténtico koan, un interrogante abierto.

No cabe duda de que su interés básico era liberar a los esclavos, y también a los esclavos de una moral de sumisión con la excusa de ayudar a los débiles. La espiritualidad de Nietzsche es una espiritualidad emancipada de los dioses y de los que someten las conciencias. En ese esentido puede también ser utilizada con provecho por las espiritualidades confesionales laicas puesto que permite liberar de la sumisión a las autoridades religiosas y de la función social del hecho religioso, dejando a la vista sobretodo el acceso libre a la realidad absoluta.

\section{Espíritu de indagación y mente amorosa}

La espiritualidad atea, por desarrollarse plenamente en período industrial ${ }^{10}$, se ha alimentado también de las expresiones de científicos emblemáticos con una intensa vida interior.

El científico se ha situado a menudo como un sujeto que estudia la naturaleza como objeto, pero frecuentemente esta distancia se ha diluido o ha desaparecido aunque sea sólo puntualmente pero de manera muy significativa. La espiritualidad se ha expresado en algunas ocasiones a través del sentimiento de sublimidad estético o a través del sentimiento de asombro, admiración y devoción de la mente ante las maravillas, por ejemplo, de la naturaleza. Estas expresiones

\footnotetext{
${ }^{10}$ La abstracción de la ciencia ha pretendido, como antaño el mito, describir la realidad, prolongando así la epistemología mítica. Ello dificulta la supervievencia de la espiritualidad atea en una sociedad de conocimiento, a no ser que la abstracción científica sea interpretada simplemente como un una construcción y, como tal, como un recusrso instrumental para apuntar a la dimensión absoluta desde la realidad relativa (CORBí, 2007, p. 182-190).
} 
espirituales ni prueban ni requieren como condición la creencia en Dios, como deja bien claro el naturalista inglés Charles Darwin ${ }^{11}$.

Einstein considera que, al igual que la religión, la experiencia científica radica en una experiencia luminosa de lo misterioso que sorprende y asombra pero sin el miedo. Se trata de una experiencia que es a la vez conocimiento y emoción. Sólo en este sentido Einstein se considera "profundamente religioso" o, para nosotros, "espiritual”. No puede aceptar creencias como un Dios personal12 o una vida eterna pero, en cambio, le basta y le sobra con el "misterio de la eternidad en la vida”, aquí y ahora, y con el "presentimiento de la maravillosa estructura de la realidad” junto al empeño humilde y sincero de "entender una parte de la razón que se manifiesta en la naturaleza”. Einstein elabora un pequeño credo de la espiritualidad del científico que puede ser muy valioso para las personas con sensibilidad espiritual que tengan dificultad en compatibilizar su interés científico con una creencia religiosa:

La experiencia más hermosa que se puede tener es la de lo misterioso. Es la emoción fundamental que está en la raíz del verdadero arte, y de la verdadera ciencia. Quien no la conoce, y ya no se puede sorprender ni sentir asombro, es como un muerto, una vela apagada. Fue la experiencia de lo misterioso (aunque teñida de miedo) la que engendró la religión. Saber la existencia de algo que no podemos aprehender, las manifestaciones de la razón más profunda y de la belleza más radiante, que solo son accesibles a nuestra razón en sus formas más elementales: son este conocimiento y esta emoción los que constituyen la verdadera actitud religiosa; en este sentido, y en ningún otro, yo soy un hombre profundamente religioso. [...]. A mí me basta con el misterio de la eternidad en la vida, y el presentimiento de la maravillosa estructura de la realidad, junto al sincero empeño por entender una parte, por ínfima que sea, de la razón que se manifiesta en la naturaleza. (EINSTEIN, 1999, p. $5)^{13}$

\footnotetext{
${ }^{11}$ DARWIN, Charles, Autobiografía, citado en HITCHENS, 2009, p. 155-156. En este sentido, me gustaria dar cabida aquí a las palabras que dirige Romain Rolland a Sigmund Freud en su carta de 5 de diciembre de 1927: "Su análisis de las religiones es justo. Pero me hubiera gustado que analizara el sentimiento religioso espontáneo, o, mas exactamente, la sensación religiosa, que es completamente diferente de las religiones propiamente dichas....el hecho simple y directo de la sensación de lo Eterno, que puede perfectamente no ser eterno, sino simplemente sin límites perceptibles y como oceánico...yo estoy familiarizado con esa sensación. A lo largo de toda mi vida no ha estado ausente de mí" (Citada en HULIN, 2007, p. 24).

${ }^{12}$ Cfr. EINSTEIN, citado en BUCKY, 1992, p. 86.

${ }^{13}$ En otro lugar afirma: "Mi religiosidad consiste en una humilde admiración del espíritu infinitamente superior que se revela en lo poco que nosotros, con nuestro entendimiento débil y transitorio, podemos comprender de la realidad." (EINSTEIN, 2013, p. 66).
} 
La razón tiene su papel en la espiritualidad atea, un papel como hemos visto más arriba, fundamental. Darwin ve esta parte de la razón que se manifiesta en la naturaleza como la "comprensibilidad lógica de las interrelaciones profundas" de la realidad, del "puro ser". Pero de hecho esta razón tiene un claro componente "religioso", que para Darwin significa aquí emocional, porque el ser humano se conmueve ante el "plan" del universo material, pero sin necesitar para nada "crear" un ser divino con voluntad y obligaciones (EINSTEIN, 2013, p. 69-70). Pero la espiritualidad de Darwin es libre, no depende de mitos ni de autoridades sino que va muy ligada a la moralidad autónoma de la acción que brota de la conciencia y que és la única que "puede conferir belleza y dignidad a la vida" (EINSTEIN, 2013, p.95).

Einstein considera la "emoción mística" como el "sentimiento religioso auténtico" de "saber que lo impenetrable existe y se manifiesta" como sabiduría y verdad en formas múltiples que deben ser descubiertas el "germen de todo el arte y la ciencia verdaderos”. Es una experiencia completamente libre del miedo (EINSTEIN en HITCHENS, 2009, p. 235). Cultivar la razón con todas sus fuerzas no aleja de la experiencia del misterio sino más bien, al contrario, la sitúa donde debe estar, en el límite, en la frontera que es la mejor manera de honrar la dignidad del misterio evitando su banalización. Uno de los pensadores que mejor lo han expresado es el filósofo austriaco Ludwig Wittgenstein que, en la segunda parte de su Tratado Lógico-filosófico, después de haber construido los fundamentos del positivismo lógico más estricto que servirá para explicar cómo es el mundo, parece apuntar con firmeza a que hay algo mucho más importante que es el culmen de su tarea y por ello afirma: "Lo místico no es cómo es el mundo, sino que el mundo es. La visión del mundo sub specie aeterni es su visión como todo (limitado). La sensación del mundo como todo limitado es lo místico." (WITTGENSTEIN, 1981, p. $151,6,44-45) .14$

\footnotetext{
14 "Los objetos sólo los puedo nombrar.Los signos son sus representantes. Sólo puedo hablar de ellos, pero no los puedo expresar.Una proposición sólo puede decir cómo es unacosa, pero no qué es." (WITTGENSTEIN, 1981, p. 76, 3, 221).
} 
Su vida personal es muy expresiva porque, después de nacer en una de las famílias judías de industriales más ricas de Europa, renuncia a todos sus bienes en favor de sus hermanos, se dedica a curar enfermos durante dos guerras, y a educar a niños en un pueblo de la montaña en total discreción y anonimato. Su vida es sorprendentemente coherente con sus escritos. Así al final de su principal escrito afirma: "Lo inexpresable, sin embargo, existe. Se muestra, es lo místico. [...]. De aquello que no se puede hablar, hay que guardar silencio" (WITTGENSTEIN, 1981, p.152, 6, 522; 7).

La verdad es que muchas veces el ser humano ha creído que el lenguaje era la expresión de la realidad y no su construcción y ello ha conllevado una epistemología mítica creyendo que el se podía agotar, controlar, manipular la realidad y que la realidad no tenía ninguna dimensión de misterio. La tarea de Wittgenstein es liberar al ser humano de esta trampa, de esta prisión que le evita volar, ir más allá: “¿Cuál es tu meta en filosofía? --Mostrarle, a la mosca, la salida de dentro de la campana del atrapamoscas" (WITTGENSTEIN, 1983, p. 196).

Esta realidad es gratuita, no utilizable porque no es útil, en el sentido de que no puede ser o quedar limitada o sometida a las necesidades egocéntricas de la estructura de necesidades que es el ser humano ${ }^{15}$.

Uno de los grandes teóricos de la espiritualidad atea es el filósofo francés André Comte-Sponville que ha aparecido con fuerza en el escenario del debate espiritual. Su aportación puede ser clarificadora porque trata explícitamente el tema de la espiritualidad atea. Este autor se inscribe en la tradición de la laicidad francesa que cada vez más en los últimos decenios ha ido postulando una laicidad positiva en la que todo ciudadano es espiritual aunque no necesariamente sea religioso, porque la religión no tiene el monopolio de lo espiritual (ALDUY, 2003,

\footnotetext{
15 "El resultado ha sido sólo que una nada haría el mismo servicio que un algo sobre el cual no se puede enunciar nada." (WITTGENSTEIN, 1983, p. 195).
} 
p. 8) ${ }^{16}$. Este escenario francés ofrece otras muestras análogas de espiritualidad atea que preparan la obra y el pensamiento de Comte-Sponville. Así el filósofo y exministro de educación Luc Ferry considera que la religiosidad después de la religión es atea (2007, p. 49), y que ello conlleva reinterpretar la religión y salvar el lenguaje religioso. En cambio el también filósofo Marcel Gauchet es más radical y considera que la filosofia debe hacer desaparecer totalmente la religión, que ya ha perdido su función social, y que en cambio los "materiales primordiales" de las religiones pueden ser utilizados con provecho por las personas espirituales pero ahora ya con categorías no religiosas (FERRY; GAUCHET, 2007, p. 30-31. 65. 69. 75. 77).

Sin embargo nuestro interés aquí se va a centrar en la reflexión emblemática de André Comte-Sponville. Define "espíritu" como un "ser finito abierto a lo infinito" (COMTE-SPONVILLE, 2007, p. 101-102). Para él, que se considera materialista (COMTE-SPONVILLE, 2014), no creer en Dios no significa renunciar a la espiritualidad, que es lo más noble, lo mejor, lo más interesante y lo más elevado de la vida humana (COMTE-SPONVILLE, 2007, p. 139-140). Pero su espiritualidad gira alrededor de la experiencia del mundo y del amor a los seres humanos que éste despierta (COMTE-SPONVILLE, 2007, p. 103). Éste es el auténtico y único misterio inmanente, el que todos los seres humanos tienen en su interior y que no necesita ningún otro de exterior o transcendente (COMTESPONVILLE, 2007, p. 112). Se trata en el fondo de un humanismo espiritual o de una espiritualidad humanista, según se mire, que tiene un cierto sabor de cristianismo secularizado encarnado y comprometido con los más pobres. Aquí no hay dios, ni dogmas, ni instituciones (COMTE-SPONVILLE, 2007, p. 123).

Pero esta experiencia no puede ir acompañada de una actitud prepotente ni orgullosa sino de una humildad sincera (COMTE-SPONVILLE, 2007, p. 128), que no cierre la puerta a la sorpresa, a la admiración, a la iluminación ante el hecho de que hay alguna cosa -el ser en sí- en lugar de nada y esta cosa es gratuita. Una admiración que se expresa en el silencio contemplativo que va más allá del

\footnotetext{
${ }^{16}$ Ver también ALDUY; OTAOLA, 2004.
} 
discurso, del conocimiento, para llegar a lo real que es últimamente inexpresable e inexplicable. Este es el ámbito de la espiritualidad, que aquí identifica con la mística, y que percibe como totalmente alejado de la religión (COMTESPONVILLE, 2007, p. 147-149), una experiencia de contemplación de la inmensidad del universo que favorece la consciencia de liberación del egocentrismo y que concede una paz profunda, libre de toda angustia (COMTE-SPONVILLE, 2007, p. 151-153). Se trata de un énstasis misterioso y evidente que el autor ha experimentado y que describe como supremamente simple, natural, intenso, deleitoso, perturbador y tranquilizador. Es una revelación sin mensaje ni secreto (COMTE-SPONVILLE, 2007, p. 158).

Pero curiosamente cuando el describe su experiemencia espiritual más intensa ésta desaparece aniquilada por la palabra, por el concepto. Una experiencia que en boca de un filósofo es todavía más expresiva, sobre todo porque no se trata de un lenguaje sobre la experiencia sino de una experiencia vivida por él mismo, de un testimonio de vida (COMTE-SPONVILLE, 2007, p. 159 -161).

No es una creencia ni una necesidad, ni una esperanza, sino más bien una presencia, pero una presencia íntima, la del místico, la del que le ha dejado de faltar Dios mismo y así Dios ya no es Dios. Una presencia que está más allá de las vicisitudes de la vida, que supera sus contradicciones, que es no dual, que es consciencia de que todo es eterno y absoluto sea cual sea el nombre que se le dé (COMTE-SPONVILLE, 2007, p. 191-193).

Una característica importante de la experiencia espiritual atea es su empatía con el dolor humano. Lo hemos visto en Nietzsche, luchador doliente, y lo vemos también ahora en Comte-Sponville. La experiencia espiritual no escapa a la experiencia radical de la desesperación propia y ajena que hace que el ser humano se dé cuenta de su finitud, de su vertiente "trágica", de que el amor no es todopoderoso sino encarnado y mortal. De hecho se edifica y cobra todo su sentido 
sobre este trasfondo, pero no se limita a él sino que surge de él, como los petalos relucientes de una flor de loto, manifestándose en el amor y la verdad de la que somos capaces, que podemos edificar nosotros mismos. Éste es el absoluto y la espiritualidad del ateo, una espiritualidad responsable que se edifica y que no depende de nada ni de nadie de fuera (COMTE-SPONVILLE, 2007, p. 203-204).

\section{Conclusión}

La espiritualidad laica y la espiritualidad atea se confunden en sus respectivas polisemias, pero, sin emabargo, se han consolidado y se manifiestan en los relatos de los maestros de la sospecha, de grandes científicos, de aventureros, de literatos, etc. Las características de esta espiritualidad son comunes con otras espiritualidades, pero presentan acentos propios y, sobre todo, son más adecuadas a la nueva antropología y a la nueva epistemología que necesita el cultivo de la cualidad humana profunda -o de la espiritualidad- en sociedades de conocimiento, basadas en el cambio y la innovación continuos. Estas espiritualidades son fruto de una laboriosa y profética liberación de dioses, creencias e instituciones sagradas, de formas y estructuras estáticas. Las espiritualidades laicas de tradición confesional y la espiritualidad atea conducen hacia la cualidad humana profunda libre y sin foma estable, que parece la única espiritualidad viable en un marco de sociedades en tránsito o de sociedades de conocimiento.

\section{REFERENCIAS}

ALDUY, Jean-Paul. Préface. In: BOLASELL, Michel. La spiritualité dans la Cité. Perpignan: Édtions Perpignan, 2003.

ALDUY, Jean-Paul; OTAOLA, Javier. Laicidad, espiritualidades en la ciudad. Perpignan: ed. Ville de Perpignan, 2004.

BUCKY, Peter A. The Private Albert Einstein. Kansas City: Andrews \&Mcmeel, 1992. COMTE-SPONVILLE, André . Home page de André Comte-Sponville. Consutable en: <http://comte-sponville.monsite-orange.fr/index.html>. Visitado en: o2 jun. 2014. 
COMTE-SPONVILLE, André. L'ànima de l'ateisme: Introducció a una espiritualitat sense Déu. Barcelona: Paidós, 2007.

CORBÍ, Marià. Hacia una espiritualidad laica - Sin creencias, sin religiones, sin dioses. Barcelona: Herder, 2007.

CORBÍ, Marià. La construcción de los proyectos axiológicos colectivos: Principios de Epistemología Axiológica. Barcelona-Madrid: CeTR-Bubok, 2013.

CORBÍ, Marià. La sabiduría de nuestros antepasados para sociedades en tránsito - Principios de Epistemología Axiolgica 2. Barcelona-Madrid: CeTR-Bubok, $2013(2)$.

DELUMEAU, Jean. Le péché et la peur : La culpabilisation en Occident XIIIe-XVIIIe siècles. Paris: Fayard, 1983.

DREWERMANN, E. Dios inmediato. Madrid: Trotta, 1997.

ECO, Umberto. Quan l'altre entra en escena, neix l'ètica. In: ECO, U. ;MARTINI, C. M. En què creuen els que no creuen. Barcelona: mpúries, 1997. p. 50-60.

EINSTEIN, Albert. Carta a un sacerdote, 20 de noviembre de 1950. In: EINSTEIN, Albert. The Human side: Glimpses from His Archives. Princenton: Princenton University Press, 2013. p. 95.

EINSTEIN, Albert. The Human side: Glimpses from His Archives. Princenton: Princenton University Press, 2013.

EINSTEIN, Albert. The World as I See It. Secaucus: The Citadel Press, 1999.

EINSTEIN, Albert. Carta a un rabino de Chicago. In: EINSTEIN, Albert. The Human side: Glimpses from His Archives. Princenton: Princenton University Press, 2013. p. 6970 .

FERRY, Luc; GAUCHET, Marcel. Lo religioso después de la religión. Barcelona: Anthropos, 2007.

FEUERBACH, L. La esencia del cristianismo. Madrid: Trotta, 1995.

FEUERBACH, L. Tesis provisionales para la reforma de la filosofía. Barcelona: Orbis, 1984 .

FEUERBACH, L. Tesis... In: KÜNG, Hans. ¿Existe Dios? Respuesta al problema de Dios en nuestro tiempo. Madrid: Cristiandad, 1979. p. 303. 345.

GALTUNG, Johan. Religions hard and soft: How to strenghten the softer aspects. In: UNESCO. The Contribution by Religions to the Culture of Peace. Barcelona: Centre UNESCO de Catalunya - Generalitat de Catalunya, 1995, p. 57-63. 
GIRARDI, G. (Ed.). L'ateismo contemporáneo. 4v. Torino: Editrize Internazionale, 1967-1970.

HITCHENS, Christopher. Dios no existe: Lecturas esenciales para el no creyente. Madrid: Debate, 2009.

HOBBES, T. Leviatan. In: HITCHENS, Christopher. Dios no existe: Lecturas esenciales para el no creyente. Madrid: Debate, 2009. p. 56.

HULIN, Michel. La mística salvaje: En las antípodas del espíritu. Madrid: Siruela, 2007.

HUME, David. Historia natural de la religión. In: HITCHENS, Christopher. Dios no existe: Lecturas esenciales para el no creyente. Madrid: Debate, 2009. p. 70-72. 80

JÜNGEL, Eberhard. Dios como misterio del mundo. Salamanca: Sígueme, 1984.

KÜNG, Hans. ¿Existe Dios? Respuesta al problema de Dios en nuestro tiempo. Madrid: Cristiandad, 1979.

LENOIR, Frédéric. Origines - Thermodynamique des dieux. Le Magazine Littéraire, Paris, n. 481, p. 54-57, 2008.

MARX, Karl. Diferencia entre la filosofía de la naturaleza de Demócrito y de Epicuro. Madrid: Ayuso, 1971.

MÜNTZER, Thomas. Tractats i sermons. Barcelona: Proa, 1989.

NIETZSCHE, F. Die Fröhliche Wissenschaft (Gaya ciencia) III. Leipzig: Verlag von E. W. Fritzsch,1882. Disponible en: <http://www.nietzschesource.org/\#eKGWB/FW>.

Visitado en: 02 jun. 2014.

NIETZSCHE, F. Ecce homo. Madrid: Alianza Editorial, 1989.

NIETZSCHE, F. El anticristo. Madrid: Alianza Editorial, 1978.

NIETZSCHE, F. La genealogía de la moral. Madrid: Alianza Editorial, 1990.

NIETZSCHE, F. Der Tolle Mensch. En: NIETZSCHE, 1882, aforismo 125. Disponible en: <http://www.nietzschesource.org/\#eKGWB/FW>. Visitado en: 02 jun. 2014.

PUENTE OJEA, Gonzalo. Ateísmo y religiosidad - Reflexiones sobre un debate. Madrid: Siglo XXI de España Editores, 1997.

TAYLOR, Charles. A Secular Age. Cambridge: Belknap Press of Harvard University Press, 2007.

TIERNO GALVÁN, Enrique. ¿Qué es ser agnóstico? Madrid: Tecnos, 1982. 
TORRADEFLOT FREIXES, Francesc (Ed.). Diálogo entre religiones: Textos fundamentales. Madrid: Trotta y Asociación UNESCO para el Diálogo Interreligioso, 2002.

TORRADEFLOT FREIXES, Francesc. El Cristianismo y el diálogo interreligioso. In: CARMONA, J. (Coord.), Historia del cristianismo: El mundo contemporáneo. v. 4. Madrid: Trotta y Universidad de Granada, 2010. p. 556-616.

TORRADEFLOT FREIXES, Francesc. L'amour et la connaissance au-delà de l'ego: Ëtude de mystique comparée de la Bhagavad-Gita et de Jean de la Croix. Barcelona: Facultat de Teologia de Catalunya, 1995.

TORRADEFLOT, Francesc. Llibertat i creativitat religiosa. Qüestions de vida cristiana, Montserrat, n.206, p. 38-47, 2002.

TORRANCE, Robert M. La búsqueda espiritua: La transcendencia en el mito, la religión y la ciencia. Madrid: Siruela, 2006.

VATTIMO, Giovanni. Creer que se cree, Barcelona: Paidós, 1996.

VOLTAIRE. Cartas filosóficas. Madrid: Alianza Editorial, 1988.

WITTGENSTEIN, L. Investigacions filosòfiques. Barcelona: Laia, 1983.

WITTGENSTEIN, L. Tractatus Logico-Philosophicus. Barcelona: Laia, 1981. 